\title{
NEW REGULARITY CONDITIONS FOR LAGRANGE AND FENCHEL-LAGRANGE DUALITY IN INFINITE DIMENSIONAL SPACES
}

\author{
Radu IOAN Boț, Sorin-Mihai Grad And Gert Wanka
}

Abstract. We give new regularity conditions expressed via epigraphs that assure strong duality between a given primal convex optimization problem and its Lagrange and Fenchel-Lagrange dual problems, respectively, in infinite dimensional spaces. Moreover we completely characterize through equivalent statements the so-called stable strong duality between the initial problem and the mentioned duals

Mathematics subject classification (2000): 49N15, 90C25, 90C34.

Keywords and phrases: Conjugate functions, Lagrange dual, Fenchel-Lagrange dual, regularity conditions, epigraphs.

\section{REFERENCES}

[1] M. Aït Mansour, A. Metrane, M. Théra, Lower semicontinuous regularization for vectorvalued mappings, Journal of Global Optimization, 35, 2 (2006), 283-309.

[2] R. I. Bot, S.-M. GRAD, G. WANKA, A new constraint qualification for the formula of the subdifferential of composed convex functions in infinite dimensional spaces, Mathematische Nachrichten, 281, 8 (2008), 1-20.

[3] R. I. Boț, S.-M. GRAD, G. WANKa, Fenchel-Lagrange versus geometric duality in convex optimization, Journal of Optimization Theory and Applications, 129, 1 (2006), 33-54.

[4] R. I. Boț, S.-M. GrAD, G. WANKA, On strong and total Lagrange duality for convex optimization problems, Journal of Mathematical Analysis and Applications, 337, 2 (2008), 1315-1325.

[5] R. I. Boț, G. WANKA, A weaker regularity condition for subdifferential calculus and Fenchel duality in infinite dimensional spaces, Nonlinear Analysis: Theory, Methods and Applications, 64, 12 (2006), 2787-2804.

[6] R. I. Boț, G. WANKA, An alternative formulation for a new closed cone constraint qualification, Nonlinear Analysis: Theory, Methods and Applications, 64, 6 (2006), 1367-1381.

[7] C. Combari, M. Laghdir, L. Thibault, Sous-différentiels de fonctions convexes composées, Annales des sciences mathématiques du Québec, 18, 2 (1994), 119-148.

[8] V. Jeyakumar, N. Dinh, G. M. LeE, A new closed cone constraint qualification for convex optimization, Applied Mathematics Report AMR, 04/8 (2004), University of New South Wales.

[9] V. Jeyakumar, W. Song, N. Dinh, G. M. Lee, Stable strong duality in convex optimization, Applied Mathematics Report AMR, 05/22 (2005), University of New South Wales.

[10] D. T. LuC, Theory of vector optimization, Springer Verlag, Berlin, 1989.

[11] J. P. Penot, M. ThÉRA, Semi-continuous mappings in general topology, Archiv der Mathematik 38 (1982), 158-166.

[12] C. ZĂLINESCU, Convex analysis in general vector spaces, World Scientific, Singapore, 2002. 